ISSN 0103-9954

\title{
EVOLUÇÃO DO USO E VALORIZAÇÃO DAS ESPÉCIES MADEIRÁVEIS DA FLORESTA ESTACIONAL DECIDUAL DO ALTO-URUGUAI, SC
}

\section{USES AND VALUATION EVOLUTION OF THE TIMBER SPECIES FROM THE BRAZILIAN SEMI- \\ -EVERGREEN FOREST OF ALTO-URUGUAI, SC}

\author{
Ademir Roberto Ruschel ${ }^{1} \quad$ Eunice Sueli Nodari ${ }^{2} \quad$ Miguel Pedro Guerra $^{3}$ Rubens Onofre Nodari ${ }^{4}$
}

\section{RESUMO}

Com base nas informações coletadas em 41 entrevistas feitas junto a madeireiros, ex-madeireiros e colonizadores, determinou-se quais as espécies potencialmente madeiráveis, o valor de uso e a valorização econômica das espécies madeiráveis para os remanescentes da Floresta Estacional Decidual na região do Alto-Uruguai, SC, desde o início da colonização daquela região. A diversidade de espécies florestais de uso madeirável conhecida popularmente na região foi de 63 espécies. Contudo, em termos de dominância esse grupo reduz-se a 15 espécies. A maior dominância foi observada para as espécies Apuleia leiocarpa, Parapiptadenia rigida, Balfourodendron riedelianum, Nectandra megapotamica, Patagonula americana, Luehea divaricata, Cedrela fissilis, Ocotea diospyrifolia, Holocalyx balansae, Myrocarpus frondosus, Cabralea canjerana e Peltophorum dubium. As espécies de maior valor comercial foram Cordia trichotoma, Cedrela fissilis, Myrocarpus frondosus e Balfourodendron riedelianum. Já Schefflera morototoni, Aralia warmingiana, Machaerium stipitatum, Chrysophyllum marginatum e várias espécies da família Lauraceae apresentaram, no decorrer do tempo, incremento no uso e na comercialização. O valor de uma espécie é condicionado tanto pela qualidade quanto pela quantidade ofertada. Em geral, verificou-se uma evolução no valor das espécies bem como na indústria madeireira que utilizou várias maneiras para se adaptar às demandas desses produtos florestais.

Palavras-chave: recursos genéticos, diversidade de espécies, usos da madeira.

\section{ABSTRACT}

Species identification and their market value and price evolution since the colonization time of the remnants of the Brazilian Semi-Evergreen Forest (Floresta Estacional Decidual do Rio Uruguai) for potential timber production was assessed through 41 questionnaires, applied to timbermen and settlers from the surrounding region. The diversity of species for timber production commonly known by the people reached 63. From the 15 predominant species is relevant to mention Apuleia leiocarpa, Parapiptadenia rigida, Balfourodendron riedelianum, Nectandra megapotamica, Patagonula americana, Luehea divaricata, Cedrela fissilis, Ocotea diospyrifolia, Holocalyx balansae, Myrocarpus frondosus, Cabralea canjerana and Peltophorum dubium. The species with the highest commercial value were: Cordia trichotoma, Cedrela fissilis, Myrocarpus frondosus and Balfourodendron riedelianum. Data from the interviews suggest that several species from the Lauraceae family and Schefflera morototoni, Aralia warmingiana, Machaerium stipitatum, Chrysophyllum marginatum had an increment in use and commercial value during the last 15 years. Changing in the commercial value of a species was pointed out as due not only to the timber quality but also to the amount of the timber availability. Overall, it was detected that the species values changed across time and that the timber industry found several ways to adapt to the demands of forest products.

Key words: genetic resources, species diversity, timber uses.

1. Engenheiro Agrônomo, M.Sc., Bolsista do CNPq. arruschel@yahoo.com.br

2. Licenciada em História, Dr ${ }^{a}$., Professora Adjunta do Departamento de História, CFH, Universidade Federal de Santa Catarina, Caixa Postal 476, CEP 88040-900, Florianópolis (SC). eunice@cfh.ufsc.br

3. Engenheiro Agrônomo, Dr., Professor Titular do Departamento de Fitotecnia, Curso de Pós-graduação em Recursos Genéticos Vegetais, Centro de Ciências Agrárias, Universidade Federal de Santa Catarina, Caixa Postal 476, CEP 88040-900, Florianópolis (SC). mpguerra@cca.ufsc.br

4. Engenheiro Agrônomo, Dr., Professor Titular do Departamento de Fitotecnia, Curso de Pós-graduação em Recursos Genéticos Vegetais, Centro de Ciências Agrárias, Universidade Federal de Santa Catarina, Caixa Postal 476, CEP 88040-900, Florianópolis (SC). nodari@ cca.ufsc.br

Recebido para publicação em 29/01/2002 e aceito em 10/04/2003. 


\section{INTRODUÇÃO}

A ocupação sistemática das terras do oeste catarinense ocorreu entre as décadas de 1920 a 1960. Após o acordo conhecido como a "Questão do Contestado", assinado entre os governos do Paraná e de Santa Catarina em 1917, esse último estabeleceu uma organização administrativa na região do Contestado, pela criação de quatro municípios, entre eles Chapecó cuja área de $13.958 \mathrm{~km}^{2}$ incluía os atuais municípios localizados a oeste. O governo, para garantir a posse definitiva das terras, entregou a colonização às companhias colonizadoras, pertencentes, em sua maioria, a empresários do Rio Grande do Sul. Competia a elas pôr em prática a opção de uma migração dirigida a grupos específicos, imigrantes alemães e italianos e descendentes das etnias estabelecidos no Rio Grande do Sul onde já haviam demonstrado a capacidade de colonizar e haviam-se mostrados ordeiros e trabalhadores. Essas etnias foram as principais responsáveis pelo povoamento do oeste de Santa Catarina (Nodari, 1999).

Tais etnias ocuparam então a Floresta Estacional Decidual, tipologia dominante naquela região, cujas categorias de uso da maior parte das espécies vegetais, segundo Chazdon et al. (1999), enquadram-se como recursos de valor medicinal $(36,4 \%)$ ou madeirável $(25,5 \%)$. Isso é relevante, porque, no Brasil, a maior parcela da população encontra, nos produtos de origem natural, a principal fonte de recurso terapêutico (Di Stasi, 1996).

Todas as terras ocupadas pelos migrantes eram lotes de pequena e média propriedade. Um fenômeno que se inicia com a vinda desses colonos, no aspecto econômico, foi o ciclo de extrativismo vegetal, em que as madeiras nobres eram extraídas ou pelas companhias colonizadoras ou pelos próprios colonos, dependendo do tipo de contrato. As principais espécies de madeira exploradas desde o início da colonização, eram Cedro, Louro, Cabreúva e Pinheiro. Estas foram extraídas, sobretudo, em áreas de fácil acesso ao rio Uruguai onde as toras formavam balsas que eram transportadas rio abaixo rumo à Argentina.

O uso do recurso florestal madeirável representou, por um período considerável do século passado, a principal atividade econômica para o estado de Santa Catarina. No início da década 40, a madeira representou mais de $20 \%$ do valor total das exportações do Estado, gerando muitos empregos diretos e indiretos e possibilitando o desenvolvimento de muitos municípios (Thomé, 1995). Posteriormente, no período de 1950-1960, a madeira representou 50\% do volume exportado no estado de Santa Catarina (Reitz et al., 1978).

As estimativas do IBGE (1990), segundo o censo realizado no final de década de 1970 e início dos anos 80, revelaram a existência de apenas 4,25\% da cobertura original, o que ainda foi reduzido posteriormente para menos que 3\% (Fundação SOS Mata Atlântica, 1998). Anteriormente, outra estimativa era ainda mais pessimista: 1,62\% (IBDF, 1984). Esses números mostram claramente que a Floresta Estacional Decidual, tida como a mais rica tipologia em número de espécies madeireiras, é um dos ecossistemas mais devastados no estado de Santa Catarina, com o agravante de não existir nenhuma reserva legal dessa tipologia no Estado. Por outro lado, a atividade extrativista de madeira de lei, nessa tipologia florestal, que foi praticada, no inicio, pelos colonizadores, visando à implantação da agricultura e pecuária, está atualmente sendo freada pela legislação ambiental, o que garante, em parte, a manutenção dos remanescentes florestais da região. No entanto, a exploração clandestina e as alterações na legislação ambiental ainda ameaçam esse ecossistema.

Com a intensa exploração, era de se esperar uma modificação na paisagem bem como uma alteração na disponibilidade de recursos florestais. Assim, nossa hipótese de trabalho é de que as espécies de alto valor comercial, exploradas no passado, estão escassas e que isso permitiria a valoração dos demais recursos. Além disso, é possível que a atual escassez dos recursos, inicialmente explorados, proporcionaria a exploração não só de outras espécies madeireiras, mas também de outros tipos de recursos genéticos cuja multiplicidade dependeria do grau de diversidade genética. Então, há a necessidade de avaliar não só a riqueza de espécies, mas também a densidade delas nos fragmentos restantes, para estabelecer suas relações com o valor dessa floresta.

Embora a região tenha sido visitada e descrita por naturalistas como Rambo, Lindman e Klein, não foram encontrados os inventários floristico e florestal pré ou pós-colonização. Existe também disponível documentação compilada de diversas fontes (exemplo: Bellani, 1996) a respeito do valor de cada tipo de

Ciência Florestal, v. 13, n. 1, 2003 
Evolução do uso e valorização das espécies madeiráveis da Floresta Estacional Decidual ...

madeira serrada para diferentes épocas e localidades. Contudo, pouca documentação a respeito da madeira antes de chegar nas serrarias. Dessa forma, a identificação das espécies que foram exploradas no passado e as que são exploradas atualmente bem como a evolução dos preços destes produtos, por meio de entrevistas com pessoas ligadas ao setor, pode revelar não só a estimativa da riqueza e da densidade das espécies existentes de maior importância, mas também a mudança na valoração, mais especificamente, daquelas que anteriormente não apresentavam valor econômico.

Assim, o objetivo deste trabalho foi identificar as espécies de uso madeireiro da Floresta Estacional Decidual do ecossistema do Alto-Uruguai e estudar os usos e a sua valoração econômica.

\section{MATERIAL E MÉTODOS}

O estudo foi desenvolvido na região do Extremo Oeste de Santa Catarina, localizado na região que abrange os Municípios de São Miguel do Oeste, Descanso, Iporã do Oeste, São João do Oeste e Itapiranga. A região é compreendida pela Floresta Atlântica tipo Estacional Decidual (IBGE, 1990). Denominou-se espécie madeirável exclusivamente aquela que apresentasse valor madeireiro para a região estudada. Tais informações foram pré-estabelecidas com base bibliográfica e, posteriormente, confirmadas pelo conhecimento tradicional, com base em entrevistas com pessoas envolvidas com o setor. As estimativas da valoração econômica, uso e densidade das espécies madeiráveis foram obtidas com base em 41 entrevistas junto aos madeireiros (13), ex-madeireiros (8) e colonizadores e seus descendentes (20) da região para os quais serão utilizadas as abreviaturas Mad, Ex-Mad e Col respectivamente. As perguntas priorizaram a obtenção das informações referentes às espécies de valor madeirável que ocorriam na região como frequiência, densidade, volumetria, uso e comércio. A elaboração das questões foi feita com base nas informações sobre a composição florística da região, feita anteriormente por Lindman (1974), Rambo (1956), Reitz et al. (1964; 1978), Klein (1972), IBDF (1984), Siqueira (1982), Brack et al. (1985), Dias et al. (1992), Carvalho (1994) e Lorenzi (1998). Os dados coletados foram processados em planilhas eletrônicas para a obtenção das estimativas de frequiência, densidade e valor de uso das espécies madeiráveis. Dentro de cada categoria de entrevistados e para cada variável analisada, foram ordenadas as dez espécies madeiráveis com maior e menor densidade e valor comercial, com base na frequeencia de respostas. As estimativas sobre o valor comercial da madeira serrada das diferentes espécies foram agrupadas por classe de espécies com base na similaridade de valor. Dessa maneira, as respostas sobre o valor comercial foram enquadradas em quatro classes (I a IV) de tal forma que o maior preço foi atribuído para as espécies agrupadas na classe I e as de menor preço na classe IV.

\section{RESULTADOS}

\section{Descrição da atividade madeireira}

A atividade madeireira na região que é característica de pequenas empresas madeireiras, teve início na década de 1930, foi crescente nas décadas posteriores, com uma rápida ascenção na década de 60. Essa última fase foi a de maior tecnificação do setor, impulsionada pela entrada da serra-fita movida à energia elétrica. O setor madeireiro continuou crescente até o final da década 70, época que faz parte do período de maior desmatamento da região que se estendeu até meados da década de 1980, segundo os entrevistados, justamente o período auge da tecnificação do setor. Seguiu-se então o declínio ou até extinção de várias madeireiras na região.

As madeireiras representaram praticamente as únicas indústrias na região e os colonizadores utilizaram a derrubada da floresta como forma de liberar o uso da terra para a agropecuária. Forneciam as toras e as madeireiras, em troca, forneciam madeira beneficiada para os colonizadores construírem as suas casas ou demais instalações agropecuárias. No início da colonização, por causa das condições de baixa tecnificação da extração, transporte e beneficiamento das toras, a produtividade era baixa e muito do recurso madeirável florestal era desperdiçado. Além disso, após a derrubada, os recursos florestais remanescentes eram queimados ou apodreciam. Para a extração, usava-se o machado ou a serra-manual. $O$ transporte dava-se por tração animal e a serragem da madeira era feita pela serra denominada pelos madeireiros da região de pica-pau, movida à roda d'água ou tanque a vapor. Dessa maneira, exploravam-se apenas as árvores que apresentavam diâmetros maiores de $50 \mathrm{~cm}$, com fustes retos e sadios, bem como as espécies madeiráveis de 
alto valor. Segundo os madeireiros, até aproximadamente 1975, as árvores cujo fuste fosse inferior a $40 \mathrm{~cm}$ de diâmetro não eram exploradas (Tabela 1).

TABELA 1: Época de início e término, modalidades de exploração e período de maior desflorestamento das atividades madeireiras na Floresta Estacional Decidual, região do Alto-Uruguai, SC.

TABLE 1: Periods, exploitation modalities and period of upmost deforestation of timber activities in the Brazilian Semi-Evergreen Forest, Alto-Uruguai river region, SC.

\begin{tabular}{|c|c|c|}
\hline Descrição da Atividade Madeireira & Período (ano) & Freqüência Relativa \\
\hline \multirow{5}{*}{ Período de início da atividade empresarial madeireira } & $1932-1942$ & 5,9 \\
\hline & $1942-1952$ & 11,8 \\
\hline & $1952-1962$ & 17,6 \\
\hline & $1962-1972$ & 52,9 \\
\hline & 1972-1982 & 11,8 \\
\hline Período de término da atividade empresarial madeireira & $1984-1994$ & 29,4 \\
\hline \multirow{5}{*}{\begin{tabular}{ll} 
Modalidades & Substituição corte manual pela moto-serra \\
\cline { 2 - 2 } de & Substituição serra-pica-pau pela serra-fita \\
exploração &
\end{tabular}} & $1966-1972$ & 100 \\
\hline & $1965-1970$ & 25 \\
\hline & $1971-1975$ & 25 \\
\hline & 1976-1980 & 25 \\
\hline & $1981-1985$ & 25 \\
\hline Periodo de maior desflorestamento & $1970-1985$ & 100 \\
\hline
\end{tabular}

Por um bom período, 15 eram as espécies exploradas para fins madeireiros em cada localidade. Porém, na região como um todo, o número de espécies exploradas era de, aproximadamente, 20. Estas estavam diretamente relacionadas ao seu valor de uso e também à sua densidade (Tabela 2).

Em meados de 1965, foram introduzidas a serra-fita movida à eletricidade e a moto-serra (Tabela 1). Já no final da mesma década, esses equipamentos, auxiliados por trator guincho e caminhão transportador de toras, se tornaram novidades entre as indústrias madeireiras. No início da década de 80, as serra-fitas já haviam substituído todas as tradicionais serras pica-pau. Essa substituição quadruplicou a produção de madeira serrada por serraria, pois com o uso da serra pica-pau eram serradas, aproximadamente, $88 \mathrm{~m}^{3} \mathrm{de}$ madeira por mês e com o uso de serra-fita esse volume passou aproximadamente para $354 \mathrm{~m}^{3} / \mathrm{mês}$. O contraste com a atualidade é expressivo: a produtividade dessas madeireiras diminuiu em mais de 60\% $(150$ $\mathrm{m}^{3} / \mathrm{mês}$ ) e as espécies exóticas representam mais de $70 \%$ deste volume.

Até 1975, as madeireiras selecionavam as árvores com diâmetros superiores a $40 \mathrm{~cm}$. Tais árvores geravam, em média, $1 \mathrm{~m}^{3}$ de madeira serrada. Tomando-se a média de madeira serrada por hectare, que foi de $43 \mathrm{~m}^{3}$, uma única madeireira com serra pica-pau era responsável pela exploração de dois hectares por mês, valor esse que passou para oito com o uso da serra-fita.

Atualmente, o setor madeireiro daquela região passa por um período muito crítico, o que levou cerca de 30\% dessas empresas a desistirem da atividade ou a migrarem, nesse caso, transferindo-se às regiões centro-oeste ou norte do País. Assim, muitas dessas empresas remanescentes no oeste de Santa Catarina instalaram filiais nessas novas regiões, de onde, também possibilitam a continuidade das empresas matrizes que atuam praticamente como beneficiadoras e revendedoras da madeira do norte.

O forte declínio da atividade madeireira na região explica-se, sobretudo, pela escassez do recurso florestal nativo que foi drasticamente reduzido. Além disso, atualmente está proibida a exploração (Decreto 750, de 10/02/1993; Resolução n. 001, de 31/01/1994). Por outro lado, o reflorestamento na região em tempos passados foi inexpressivo. Daí a inexistência de matéria-prima em abundância. Uma terceira razão é a concorrência das madeiras provenientes do norte do País. Essa realidade caracterizada pela insustentabilidade do setor madeireiro imprime à atividade o caráter nômade e insustentável que ainda segue em direção às novas fronteiras florestais no Brasil.

\section{Espécies madeireiras}

O conhecimento popular levantado nas entrevistas reconheceu 63 espécies madeiráveis, sendo 44 delas mencionadas pela maioria dos informantes (Tabela 2). As outras 19 espécies foram reconhecidas 
TABELA 2: Espécies de valor madeirável sem restrição de uso, conforme denominação popular e provável denominação científica da Floresta Estacional Decidual, região do Alto-Uruguai, SC.

TABLE 2: Species with timber value without constraint of use, according to popular designation and probable scientific name from Brazilian Semi-Evergreen Forest, Alto-Uruguai river region, SC.

\begin{tabular}{|c|c|c|}
\hline Família & Provável Espécie Científica & Nome Comum \\
\hline Apocynaceae & Aspidosperma parvifolium DC. & Piquiá \\
\hline Araliaceae & Schefflera morototonii ( Aubl.) Maguire, Steyermark et Frodin & Caxeta, mandiocão \\
\hline Bignoniaceae & $\begin{array}{l}\text { Jacaranda micrantha Cham. } \\
\text { Tabebuia alba (Cham.) Sandw. } \\
\text { Tabebuia heptaphylla (Vell.) Toledo }\end{array}$ & $\begin{array}{l}\text { Caroba } \\
\text { Ipê-amarelo } \\
\text { Ipê-roxo, ipê-preto }\end{array}$ \\
\hline Boraginaceae & $\begin{array}{l}\text { Cordia ecalyculata Vell. } \\
\text { Cordia trichotoma (Vell.) Arrab. Ex Steud. } \\
\text { Patagonula americana L. }\end{array}$ & $\begin{array}{l}\text { Louro-branco } \\
\text { Louro, louro-pardo } \\
\text { Guajuvira }\end{array}$ \\
\hline Caesalpinaceae & $\begin{array}{l}\text { Apuleia leiocarpa (Vogel) Macbride } \\
\text { Holocalyx balansae Micheli } \\
\text { Peltophorum dubium (Spreng.) Taubert }\end{array}$ & $\begin{array}{l}\text { Grápia } \\
\text { Alecrim } \\
\text { Canafístula }\end{array}$ \\
\hline Erythroxylaceae & Erythroxylum deciduum A. St. -Hil. & Concon \\
\hline Lauraceae & $\begin{array}{l}\text { Nectandra grandiflora Nees et Mart. Ex Nees } \\
\text { Nectandra lanceolata Nees et Mart. Ex Nees } \\
\text { Nectandra megapotamica (Spreng) Mez } \\
\text { Ocotea diospyrifolia (Meissner) Mez } \\
\text { Ocotea puberula (A. Rich.) Nees }\end{array}$ & $\begin{array}{l}\text { Canela-amarela } \\
\text { Canela-amarela } \\
\text { Canela-preta/merda } \\
\text { Canela-loura/pinha } \\
\text { Canela-sebo }\end{array}$ \\
\hline Meliaceae & $\begin{array}{l}\text { Cabralea canjerana (Vell.) Mart. } \\
\text { Cedrela lilloi C.de Candolle } \\
\text { Cedrela fissilis Vell. }\end{array}$ & $\begin{array}{l}\text { Canjerana } \\
\text { Cedro } \\
\text { Cedro }\end{array}$ \\
\hline Mimosaceae & $\begin{array}{l}\text { Albizia niopoides (Spruce ex Benth.) Burkart } \\
\text { Albizia edwallii (Hoehne) Barnely et J. Grimes } \\
\text { Enterolobium contortisiliquum (Vell.) Morong } \\
\text { Parapiptadenia rigida (Benth.) Brenan } \\
\end{array}$ & $\begin{array}{l}\text { Angico-branco } \\
\text { Angico-branco } \\
\text { Timbaúva } \\
\text { Angico-vermelho }\end{array}$ \\
\hline Moraceae & Maclura tinctoria (L.) Don ex Steudel & Tajaúva \\
\hline Papilionaceae & $\begin{array}{l}\text { Dalbergia frutescens (Vell.) Britton } \\
\text { Lonchocarpus campestris Mart. Ex Benth. } \\
\text { Lonchocarpus muhlbergianus Hassler } \\
\text { Lonchocarpus neuroscapha Benth. } \\
\text { Machaerium paraguariense Hassl, } \\
\text { Machaerium nictitans (Vell.) Benth. } \\
\text { Machaerium stipitatum Vogel } \\
\text { Myrocarpus frondosus } \text { M. Alemão }\end{array}$ & $\begin{array}{l}\text { Farinha-seca, marmeleiro } \\
\text { Rabugio, rabo-de-bugio } \\
\text { Rabugio } \\
\text { Rabugio } \\
\text { Rabugio } \\
\text { Rabugio-amarelo } \\
\text { Canela-brejo } \\
\text { Cabreúva }\end{array}$ \\
\hline Polygonaceae & Ruprechtia laxiflora Meissner & Marmeleiro \\
\hline Rosaceae & Prunus sellowii Koehne & Pessegueiro-brabo \\
\hline Rutaceae & $\begin{array}{l}\text { Baulfourodendron reidelianum ( Engl.) Engl. } \\
\text { Helietta apiculata Benth. } \\
\text { Zanthoxylum rhoifolium L. }\end{array}$ & $\begin{array}{l}\text { Guatambú } \\
\text { Canela-veado } \\
\text { Mamica-de-cadela }\end{array}$ \\
\hline Sapindaceae & $\begin{array}{l}\text { Cupania vernalis Cambess. } \\
\text { Diatenopteryx sorbifolia Radlk. } \\
\text { Matayba elaeagnoides Radlk. }\end{array}$ & $\begin{array}{l}\text { Camboatá } \\
\text { Maria-preta } \\
\text { Camboatá-branco }\end{array}$ \\
\hline Sapotaceae & Chrysophyllum marginatum (Hook. et Arn.) Radlk. & Vassourinha \\
\hline Tiliaceae & Luehea divaricata Mart. et Zucc. & Açoita, açoita-cavalo \\
\hline Verbenaceae & Vitex megapotamica (Spreng.) Mold. & Tarumã \\
\hline
\end{tabular}

por uma minoria dos informantes (Tabela 3). O número de espécies apresentadas é uma estimativa que deve ser tomada com cautela, pois o conhecimento popular, muitas vezes, toma um mesmo nome para espécies científicas diferentes, observando-se também o contrário, o que de fato ocorreu principalmente com o grupo das espécies pertencentes às famílias das leguminosas e lauráceas. Como exemplo, pode-se observar que várias espécies foram denominadas simplesmente como canela, ou então, a denominação era baseada em 
alguma característica relacionada com a cor, cheiro ou textura da madeira.

TABELA 3: Espécies de valor madeirável restrito, conforme denominação popular e provável denominação científica na Floresta Estacional Decidual, região do Alto-Uruguai, SC.

TABLE 3: Species with restrict timber value, according to popular designation and probable scientific names from Brazilian Semi-Evergreen Forest, Alto-Uruguai river region, SC.

\begin{tabular}{lll}
\hline Família & Provável Espécie Científica & Nome Comum \\
\hline Anonaceae & Rollinia rugulosa Schltdl. & Araticum \\
\hline Apocynaceae & Rauvolfia selollowii Müll. Arg. & Pau-para-tudo, pau-amargo \\
\hline Araliaceae & Aralia warmingiana (March.) J. Wen & Cinamão-do-mato, carobão \\
\hline Bombacaceae & Chorisia speciosa A. St. -Hil. & Paineira, algodoeiro \\
\hline Euphorbiaceae & Alchornea sidifolia Müll. Arg. & Tapiá, canela-raposa, "Fass-canelle" \\
& Alchornea triplinervia (Spreng.) Müll. Arg. & Tapiá, canela-raposa, "Fass-canelle" \\
& Sapium glandulatum (Vell.) Pax. & Leiteiro \\
& Tetrorchidium rubrivenium Poepp. et Endl. & Canemuçu \\
& Sebastiania brasiliensis Spreng. & Branquilho \\
\hline Ebenaceae & Diospyros inconstans Jacq. & Fruto-do-jacu \\
\hline Flacourtiaceae & Casearia sylvestris Sw. & Guaçatonga, chá-de-bugre \\
\hline Myrtaceae & Eugenia pyriformis Cambess. & Uvaia \\
& Myrcianthes pungens (O. Berg) D. Legr. & Guabiju \\
\hline Papilionaceae & Plinia trunciflora (O. Berg) Kausel & Jabuticabeira \\
\hline Sapotaceae & Chrysophyllum gonocarpum (Mart. et Eichl.) Engl. & Corticeira \\
\hline Rutaceae & Pilocarpus pennatifolius Lem. & Passos-de-anta/ caxeta-amarela \\
\hline Simaroubaceae & Picrasma crenata (Vell.) Engl. & Pau-canzil \\
\hline Styracaceae & Styrax leprosus Hook. et Arn. & Quina \\
\hline
\end{tabular}

As espécies que apresentaram maior densidade para a região foram respectivamente: grápia, angicovermelho, guatambu, açoita-cavalo, canela-loura, guajuvira, alecrim, canela-pinha, cabreúva e canjerana (Tabela 4). Embora a lista das 10 espécies de maior densidade não foram as mesmas para as diferentes

TABELA 4: Freqüêcia de respostas (\%) sobre as espécies de valor madeirável de maior densidade na Floresta Estacional Decidual, região do Alto-Uruguai, SC.

TABLE 4: Frequency of answers (\%) about the species with timber value of highest densities from Brazilian Semi-Evergreen Forest, Alto-Uruguai river region, SC.

\begin{tabular}{l|cc|c|c}
\hline \multirow{2}{*}{ Nome Comum } & \multicolumn{3}{|c|}{ Categoria de Entrevistados } & \multirow{2}{*}{ Total } \\
\cline { 2 - 4 } & $\begin{array}{c}\text { Colonizadores } \\
\mathrm{n}=20\end{array}$ & $\begin{array}{c}\text { Madeireiros } \\
\mathrm{n}=13\end{array}$ & $\begin{array}{c}\text { Ex-madeireiros } \\
\mathrm{n}=8\end{array}$ & \\
\hline Grápia & 100 & 100 & 100 & 100,0 \\
Angico-vermelho & 95 & 100 & 100 & 98,3 \\
Guatambu & 85 & 92 & 88 & 88,3 \\
Açoita-cavalo & 80 & 85 & 88 & 84,3 \\
Canela-loura & 75 & 92 & 75 & 80,7 \\
Guajuvira & 70 & 92 & 75 & 79,0 \\
Alecrim & 80 & 69 & 63 & 70,7 \\
Cedro & 55 & 77 & 63 & 65,0 \\
Canela-pinha & 60 & 92 & 38 & 63,3 \\
Cabreúva & 70 & 69 & 50 & 63,0 \\
Canjerana & 75 & 38 & 75 & 62,7 \\
Canafístula & 40 & 62 & 63 & 55,0 \\
Maria-preta & 65 & 46 & 38 & 49,7 \\
Rabugio & 30 & 69 & 50 & 49,7 \\
Pessegueiro-brabo & 30 & 38 & 63 & 43,7 \\
\hline
\end{tabular}

Em que: $\mathrm{n}=$ tamanho da amostra. 
categorias de entrevistados, as sete primeiras citadas são comuns e as que ocorreriam em maior frequiência. Embora as espécies, alecrim, canela-pinha, canjerana e cabreúva na freqüência geral das entrevistas aparecem entre as 10 espécies de maior densidade, estas não foram as mais freqüentes em, pelo menos, uma das categorias de entrevistados. Nesse caso, tais espécies foram substituídas por uma das seguintes espécies: cedro, maria-preta, canafístula, rabugio, vassourinha, canela-amarela e pessegueiro-brabo.

TABELA 5: Freqüência de respostas (\%) sobre as espécies madeiráveis de baixa densidade na Floresta Estacional Decidual, região do Alto-Uruguai, SC.

TABLE 5: Frequency of answers (\%) about the species with timber value of lowest densities from Brazilian Semi-Evergreen Forest, Alto-Uruguai river region, SC.

\begin{tabular}{l|c|c|c|c}
\hline \multirow{2}{*}{ Nome Comum } & \multicolumn{3}{|c|}{ Categoria de Entrevistados } & \multirow{2}{*}{ Total } \\
\cline { 2 - 4 } & $\begin{array}{c}\text { Colonizadores } \\
\mathrm{n}=20\end{array}$ & $\begin{array}{c}\text { Madeireiros } \\
\mathrm{n}=13\end{array}$ & $\begin{array}{c}\text { Ex-madeireiros } \\
\mathrm{n}=8\end{array}$ & \\
\hline Timbaúva & 94 & 85 & 86 & 88,3 \\
Caxeta, madiocão & 89 & 92 & 71 & 84,0 \\
Caroba & 78 & 100 & 71 & 83,0 \\
Angico-branco & 83 & 69 & 86 & 79,3 \\
Mamica-de-porca & 78 & 69 & 86 & 77,7 \\
Piquiá & 70 & 69 & 88 & 75,7 \\
Terramão & 75 & 54 & 88 & 72,3 \\
Camboatá & 70 & 46 & 100 & 72,0 \\
Marmeleiro & 70 & 46 & 100 & 72,0 \\
Canela-brejo & 70 & 54 & 88 & 70,7 \\
Corticeira & 85 & 31 & 88 & 68,0 \\
Louro-pardo & 65 & 38 & 88 & 63,7 \\
Guabiju & 60 & 46 & 75 & 60,3 \\
Tajaúva & 40 & 62 & 75 & 59,0 \\
Canela-veado & 60 & 38 & 75 & 57,7 \\
Canela-amarela & 65 & 31 & 75 & 57,0 \\
Concon & 75 & 46 & 50 & 57,0 \\
Ipê-roxo & 20 & 69 & 63 & 50,7 \\
\hline
\end{tabular}

Em que: $\mathrm{n}=$ tamanho da amostra.

Para as espécies madeiráveis citadas com baixa frequiência na região, sobressaíram-se timbaúva, caxeta, caroba, angico-branco, mamica-de-porca, piquiá, terramão e várias outras (Tabela 5). Contudo, observa-se que há diferenças nas quantidades de vezes que uma espécie foi citada, quando se comparam as categorias de entrevistados (exemplo: do ipê-roxo, com frequência de 20\% entre os colonizadores e 69\% entre os madeireiros). Essa discrepância pode ter sido afetada pela diferença nas densidades dessas espécies e pela falta de profundo conhecimento dos entrevistados sobre a fitossociologia da floresta na região.

As espécies apontadas com o maior número de usos foram respectivamente: cabreúva, canela-loura, louro, cedro, pinheiro, guatambu e por outro lado, entre as que apresentaram apenas um tipo de uso, podem ser mencionadas, a corticeira, terramão, canela-veado e 10 outras (Tabela 6). As espécies que apresentaram menor número de usos, apresentaram também baixas freqüências nas citações dos informantes, com exceção de terramão, caroba e canela-do-brejo.

Dessa forma, eram utilizadas, pelo menos, 13 espécies como madeireiras cujos usos se destinavam para madeira quadrada, assoalho, móveis, tabuado, ripado e foro. Para cada um destes e dos demais usos mencionados na Tabela 6, pelo menos havia a possibilidade de utilização de três espécies.

Das cinco espécies de maior valor de uso e comercial, quatro espécies (cedro, louro-pardo, cabreúva e guatambu) foram as mais frequientemente citadas em todas as categorias dos entrevistados (Tabela 7). Por outro lado, pinheiro e ipê-roxo, foram espécies reconhecidas por todos como de alto valor madeireiro. Contudo, por causa da distribuição restrita destas, elas ficaram em desvantagem na classificação por frequiência na valoração, sobressaindo-se as demais espécies mais freqüientes na região. 
TABELA 6: Freqüêcia de respostas $(\%)$ nas entrevistas com colonizadores $(n=20)$, madeireiros $(n=13)$, ex-madeireiros $(\mathrm{n}=8)$, quanto ao uso das espécies florestais na Floresta Estacional Decidual, região do Alto-Uruguai, $\mathrm{SC}$ ( $\mathrm{n}=$ tamanho da amostra).

TABLE 6: Frequency of answers $(\%)$ in the interviews with Settlers $(n=20)$, Timbermen $(n=13)$ and Ex-Timbermen $(n=8)$ about the type of use of forest species from Brazilian Semi-Evergreen Forest, Alto-Uruguai river region, $\mathrm{SC}(\mathrm{n}=$ size of the sample).

\begin{tabular}{|c|c|c|c|c|c|c|c|c|c|c|c|c|c|c|c|c|c|c|c|c|}
\hline Espéies & 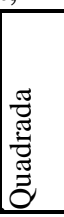 & 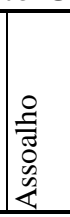 & 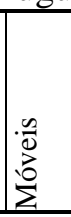 & 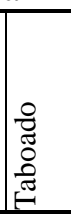 & 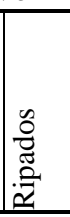 & $\begin{array}{l}\stackrel{0}{0} \\
0 \\
\vdots \pm\end{array}$ & 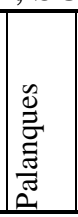 & 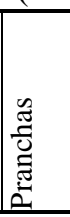 & 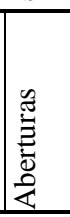 & 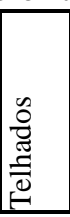 & 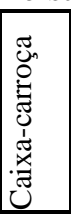 & 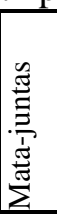 & 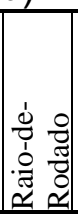 & 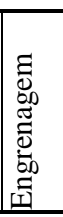 & 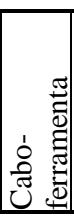 & & 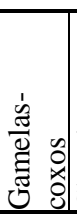 & 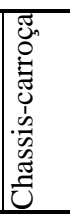 & 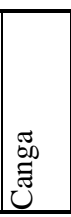 & 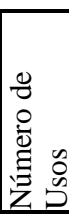 \\
\hline Cabreúva & 21 & 96 & 20 & 16 & - & 12 & 4 & 8 & 17 & 100 & 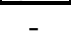 & - & 61 & 56 & - & 70 & - & - & 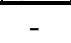 & 12 \\
\hline Canela-loura & 13 & 16 & 16 & 24 & 24 & 16 & - & 33 & 25 & - & 11 & 4 & 6 & - & - & - & - & - & 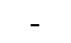 & 11 \\
\hline Louro & 29 & 16 & 56 & 8 & 44 & 60 & - & - & 92 & - & - & 76 & - & 6 & 78 & - & - & - & - & 10 \\
\hline Cedro & - & 12 & 84 & 36 & - & 68 & - & - & 88 & - & 11 & 88 & 6 & 6 & - & - & 83 & - & - & 10 \\
\hline Pinheiro & - & 40 & 32 & 32 & 12 & 52 & - & - & 13 & 17 & 44 & 20 & - & - & - & 5 & - & - & - & 10 \\
\hline Guatambú & 13 & 100 & 28 & 20 & 48 & - & - & 4 & 13 & 17 & - & - & - & - & 78 & - & - & - & - & 9 \\
\hline Guajuvira & 42 & 4 & 12 & - & - & - & 100 & 21 & 13 & - & - & - & 61 & - & 83 & - & - & 17 & - & 9 \\
\hline Grápia & 33 & 68 & 4 & 92 & - & - & 4 & 38 & 8 & 94 & - & - & - & - & - & 95 & - & - & - & 9 \\
\hline Angico & 83 & 4 & - & 36 & - & - & 54 & 67 & - & 17 & - & - & 39 & - & - & 5 & - & 100 & - & 9 \\
\hline Açoita & 29 & - & 8 & 12 & 16 & 24 & & - & - & - & 6 & - & - & - & - & - & - & - & 56 & 7 \\
\hline Canjerana & - & 76 & - & 20 & - & - & 46 & 46 & 17 & 22 & - & - & - & - & - & - & 17 & - & - & 7 \\
\hline Canela-pinha & 8 & - & - & 8 & - & 12 & - & - & - & - & 44 & 4 & - & - & - & - & 6 & - & - & 6 \\
\hline Canelas & 50 & - & - & 28 & 44 & 20 & - & - & - & - & 28 & 4 & - & - & - & - & - & - & - & 6 \\
\hline Ipês & 17 & 8 & - & - & - & - & 8 & - & - & - & - & - & 39 & 28 & - & 15 & - & - & - & 6 \\
\hline Timbaúva & - & 4 & 4 & 40 & - & - & - & - & - & 17 & 67 & - & - & - & - & - & 67 & - & - & 6 \\
\hline Canafístula & 13 & 12 & - & 76 & - & - & - & 8 & - & - & - & - & - & 6 & - & - & - & - & - & 5 \\
\hline Tajaúva & - & 4 & 4 & - & - & - & - & - & - & - & - & - & 11 & 28 & - & - & - & - & - & 4 \\
\hline lecrim & 4 & - & 4 & - & - & - & 21 & - & - & - & - & - & - & 6 & - & - & - & - & - & 4 \\
\hline Marmeleiro & 46 & - & - & 8 & 16 & - & - & - & - & - & - & - & - & - & - & - & - & - & - & 3 \\
\hline Pessegueiro & 33 & - & - & - & 32 & 4 & - & - & - & - & - & - & - & - & - & - & - & - & - & 3 \\
\hline Piquiá & - & 28 & 28 & - & - & - & - & - & - & - & - & - & - & - & - & 10 & - & - & - & 3 \\
\hline Canela-brejo & - & - & - & - & - & - & - & - & - & - & - & - & - & - & - & - & - & 6 & 100 & 2 \\
\hline Maria-preta & 13 & - & - & - & 4 & - & - & - & - & - & - & - & - & - & - & - & - & - & - & 2 \\
\hline Caxeta & - & - & - & - & 4 & 4 & - & - & - & - & - & - & - & - & - & - & - & - & - & 2 \\
\hline Canela-amarela & - & - & - & - & 8 & - & - & - & - & - & 6 & - & - & - & - & - & - & - & - & 2 \\
\hline Louro-branco & - & - & - & - & - & 4 & - & - & - & - & - & 4 & - & - & - & - & - & - & - & 2 \\
\hline Caroba & - & - & 96 & - & - & 4 & - & - & - & - & - & - & - & - & - & - & - & - & - & 2 \\
\hline Rabugio & - & 4 & - & - & - & - & - & 4 & - & - & - & - & - & - & - & - & - & - & - & 2 \\
\hline Ariticum & - & - & - & - & - & - & - & - & - & - & - & - & - & - & - & - & - & - & 6 & 1 \\
\hline Angico-branco & - & - & - & - & - & - & - & - & - & - & - & - & - & - & - & - & - & 17 & - & 1 \\
\hline Camboatá & 4 & - & - & - & - & - & - & - & - & - & - & - & - & - & - & - & - & - & - & 1 \\
\hline Carne-vaca & - & - & - & - & - & 4 & - & - & - & - & - & - & - & - & - & - & - & - & - & 1 \\
\hline Guabijú & - & - & - & - & - & - & - & - & - & - & - & - & - & 6 & - & - & - & - & - & 1 \\
\hline Mamica-porca & - & - & - & - & - & - & - & - & - & - & - & - & - & - & 6 & - & - & - & - & 1 \\
\hline Uvaia & - & - & - & - & - & - & - & - & - & - & - & - & - & - & 6 & - & - & - & - & 1 \\
\hline Cereja & - & - & - & - & - & - & - & - & - & - & - & - & - & - & 17 & - & - & - & - & 1 \\
\hline Vassourinha & - & - & - & - & 4 & - & - & - & - & - & - & - & - & - & - & - & - & - & - & 1 \\
\hline Coqueiro & - & - & - & - & 40 & - & - & - & - & - & - & - & - & - & - & - & - & - & - & 1 \\
\hline Canela-veado & - & - & - & - & - & - & 4 & - & - & - & - & - & - & - & - & - & - & - & - & 1 \\
\hline Terramão & - & - & - & - & - & - & 88 & - & - & - & - & - & - & - & - & - & - & - & - & 1 \\
\hline Corticeira & - & - & - & - & - & - & - & - & - & 6 & - & - & - & - & - & - & - & - & - & 1 \\
\hline N. espécies citadas & 17 & 16 & 15 & 15 & 13 & 13 & 9 & 9 & 9 & 8 & 8 & 7 & 7 & 7 & 6 & 6 & 4 & 4 & 3 & - \\
\hline
\end{tabular}


TABELA 7: Frequiência de respostas (\%) sobre as espécies mencionadas de maior valor madeirável (de 1927 a 1999), na Floresta Estacional Decidual, região do Alto-Uruguai, SC.

TABLE 7: Frequency of answers (\%) about the mentioned species with highest commercial value (from 1927 to 1999) from Brazilian Semi-Evergreen Forest, Alto-Uruguai river region, SC.

\begin{tabular}{l|c|c|c|c}
\hline \multirow{2}{*}{ Nome Comum } & \multicolumn{2}{|c|}{ Categoria de entrevistados } & \multirow{2}{*}{ Média } \\
\cline { 2 - 4 } & $\begin{array}{c}\text { Colonizadores } \\
\mathrm{n}=20\end{array}$ & $\begin{array}{c}\text { Madeireiros } \\
\mathrm{n}=13\end{array}$ & $\begin{array}{c}\text { Ex-madeireiros } \\
\mathrm{n}=8\end{array}$ & \\
\hline Cedro & 100 & 100 & 100 & 100 \\
Cabreúva & 90 & 100 & 100 & 96,7 \\
Louro-pardo & 100 & 100 & 88 & 96,0 \\
Guatambu & 85 & 92 & 88 & 88,3 \\
Grápia & 60 & 50 & 63 & 57,7 \\
Pinheiro & 35 & 54 & 75 & 54,7 \\
Ipê-roxo & 20 & 54 & 25 & 33,0 \\
\hline
\end{tabular}

Em que: $\mathrm{n}=$ tamanho da amostra.

Entre as espécies não-exploradas comercialmente até os anos de 1970 e que atualmente apresentam valor comercial, foram citadas mais freqüentemente a caxeta e a corticeira (Tabela 8). Diferenças de até $30 \%$ entre as respostas das categorias de entrevistados foram detectadas para seis das 13 espécies. Para as demais houve uma concordância considerada razoável.

TABELA 8: Frequiência de respostas (\%) sobre as espécies madeiráveis não-exploradas comercialmente até os anos 1970 na Floresta Estacional Decidual, região do Alto-Uruguai, SC.

TABLE 8: Frequency of answers (\%) about the not commercially exploited species until 1970 from Brazilian Semi-Evergreen Forest, Alto-Uruguai river region, SC.

\begin{tabular}{lcc|c|c}
\hline \multirow{2}{*}{ Nome Comum } & \multicolumn{3}{|c|}{ Categoria de entrevistados } & \multirow{2}{*}{ Total } \\
\cline { 2 - 4 } & $\begin{array}{c}\text { Colonizadores } \\
\mathrm{n}=20\end{array}$ & $\begin{array}{c}\text { Madeireiros } \\
\mathrm{n}=13\end{array}$ & $\begin{array}{c}\text { Ex-madeireiros } \\
\mathrm{n}=8\end{array}$ & \\
\hline Caxeta & 100 & 100 & 100 & 100 \\
Corticeira & 91 & 83 & 88 & 87 \\
Rabugio & 82 & 83 & 100 & 87 \\
Mamica-de-cadela & 82 & 50 & 88 & 71 \\
Maria-preta & 64 & 67 & 63 & 69 \\
Alecrim & 82 & 50 & 63 & 65 \\
Camboatá & 73 & 58 & 63 & 65 \\
Carne-de-vaca & 82 & 50 & 63 & 65 \\
Vassourinha & 82 & 42 & 75 & 65 \\
Pessegueiro-brabo & 67 & 67 & 50 & 63 \\
Canela-pinha & 53 & 56 & 75 & 59 \\
Canela-veado & 73 & 42 & 63 & 58 \\
Caxeta-amarela & 60 & 22 & 50 & 47 \\
\hline
\end{tabular}

Em que: $\mathrm{n}=$ tamanho da amostra.

As informações sobre o rendimento do volume de madeira serrada, em metros cúbicos por hectare das espécies florestais da região, revelaram uma grande amplitude: de 30 a $60 \mathrm{~m}^{3} /$ ha (Tabela 9), provavelmente em face do reduzido tamanho da amostra utilizada. Contudo, tal discrepância também pode ser dependente das diferenças entre os fragmentos de onde as madeiras são retiradas, pois estes podem encontrar-se em estádios sucessionais diferenciados, além de inseridos em condições edáficas diferentes. A média de todas as madeireiras sobre o rendimento de madeira serrada da região foi de $43 \mathrm{~m}^{3} / \mathrm{ha}$.

Os valores pagos por hectare florestal no passado foram fornecidos com referência ao valor do quilo de suíno-gordo-vivo, ou sobre a percentagem sobre o montante de madeira na floresta. Em termos comparativos, o valor pago a $1000 \mathrm{~kg}$ de suíno-vivo-gordo em períodos anteriores a 1990, era de $\mathrm{R} \$$ 1.060,00 (Instituto CEPA, 1999), valor esse considerado uma estimativa, segundo alguns dos entrevistados, 
da madeira contida num hectare florestal. Os preços pagos em abril de 1999 foram tomados diretamente em reais cuja média alcançou o valor de 897 reais (desvio padrão de 85,1) (Tabela 9).

TABELA 9: Rendimento do volume de madeira serrada por hectare $\left(\mathrm{m}^{3} / \mathrm{ha}\right)$ e valor pago por hectare em abril de 1999 (R \$/ha), na Floresta Estacional Decidual, região do Alto-Uruguai, SC.

TABLE 9: Volume yield of sawnwood per hectare (m3/ha) and value paid per hectare in April of 1999 (R\$/ha) of species from Brazilian Semi-Evergreen Forest, Alto-Uruguai river region, SC.

\begin{tabular}{lcc}
\hline Madeireiras & $\mathrm{m}^{3} / \mathrm{ha}$ & $\mathrm{R} \$ / \mathrm{ha}$ \\
\hline $\mathrm{A}$ & 60 & 750 \\
$\mathrm{~B}$ & 50 & 750 \\
$\mathrm{C}$ & 42 & 840 \\
$\mathrm{D}$ & 30 & 850 \\
$\mathrm{E}$ & 55 & 870 \\
$\mathrm{~F}$ & 35 & 900 \\
$\mathrm{G}$ & 45 & 900 \\
$\mathrm{H}$ & 50 & 950 \\
$\mathrm{I}$ & 35 & 950 \\
$\mathrm{~J}$ & 36 & 1.000 \\
$\mathrm{~K}$ & 35 & 1.000 \\
L & 40 & 1.000 \\
\hline Média & 43 & 897 \\
Desvio-padrão & 8,9 & 85,1 \\
\hline
\end{tabular}

Em 1940, no município de Chapecó, que abrangia a região estudada, o preço do $\mathrm{m}^{3}$ em tora de cedro e louro era 122\$000, enquanto uma cabeça de suíno vivo tinha o valor de $90 \$ 000$ (Instituto de Geografia e Estatística, 1942). Esses dados demonstram dois importantes aspectos. Em primeiro lugar que o cedro e o louro tinham o mesmo preço e que o valor das madeiras crescia enormemente depois que chegava à serraria.

Tomando-se $10 \%$ do volume florestal serrado, que era também um dos tipos de transação comercial na época, bem como a média dos valores pagos em abril de 1999 por espécie (Tabela 10), obter-se-á o valor de $\mathrm{R} \$ 985,00$ por hectare recebido pelo proprietário das espécies madeireiras, valor esse muito similar ao pago em abril de 1999 pelo conjunto de espécies (Tabela 9). Um segundo tipo de negócio mencionado se refere ao pagamento ao proprietário da terra em volume de madeira mista pelo madeireiro, volume esse que poderia variar conforme a riqueza madeirável do remanescente florestal, o que geralmente compreendia um volume de até $21 \mathrm{~m}^{3}$ de madeira mista por hectare florestal. Esse tipo de transação remuneraria aproximadamente $\mathrm{R} \$ 2.500,00$ por hectare, estimado com base na média dos valores das espécies incluídas na Tabela 10. Nessas estimativas se pode verificar que os preços pagos por hectare florestal não seguem um padrão definido e dependem da riqueza madeirável e do tipo de negociação.

Em termos gerais, as informações obtidas referentes ao valor comercial do $\mathrm{m}^{3}$ de madeira serrada demonstraram uniformidade entre os informantes. As ressalvas que os informantes faziam foram quanto à especificidade do preço que não é somente componente da espécie de madeira, pois a qualidade, avaliada pelo aspecto visual (carunchado/bichado, largura e comprimento do produto) e a homogeneidade do produto e a quantidade da oferta (em volume por espécie) agregam valor ao produto final. Um exemplo é a comercialização da madeira mista (mistura de várias espécies), estratégia usada pelos madeireiros para viabilizar o comércio no setor. $\mathrm{O}$ menor preço desta em relação a lotes homogêneos supera os problemas decorrentes tanto da escassez como da baixa qualidade de alguns produtos florestais.

Os valores comerciais do $\mathrm{m}^{3}$ de madeira serrada das diferentes espécies foram agrupados em quatro classes: as de maior valor classe I ( $\mathrm{R} \$ 353,00)$, e as de menor na classe IV (R\$ 110,00). A classe IV apresentou preço inferior às espécies exóticas ( $\mathrm{R} \$ 119,00)$ atualmente em cultivo (Tabela 10). $\mathrm{O}$ maior número de espécies foi agrupado na classe III (26 espécies). As espécies classificadas para as classes III e classe IV apresentaram, na grande maioria, baixa frequiência no ecossistema florestal (Tabela 5).

Ciência Florestal, v. 13, n. 1, 2003 
TABELA 10: Classes de valor em reais $(\mathrm{R} \$)$ da madeira serrada por grupo de espécies madeiráveis (denominações populares) em abril de 1999 na Floresta Estacional Decidual, região do Alto-Uruguai, SC.

TABLE 10: Classes of values in Reais (R\$) of sawnwood per group of timber species (popular designation) in April of 1999 from Brazilian Semi-Evergreen Forest, Alto-Uruguai river region, SC.

\begin{tabular}{|c|c|c|}
\hline \multicolumn{3}{|c|}{ Classe I - R \$ 353,00 } \\
\hline Açoita-cavalo & Caroba & Louro pardo \\
\hline Cabreúva & Carvalho & Ipê-amarelo/roxo \\
\hline Cedro & Guatambu & Piquiá \\
\hline \multicolumn{3}{|c|}{ Classe II - R\$ 229,00 } \\
\hline Angico & Canjerana & Pinheiro \\
\hline Canafístula & Concon & Tajuva \\
\hline Canela-amarela & Guajuvira & Timbaúva \\
\hline Canela-branca & Grápia & \\
\hline Canela-louro & Marmeleiro & \\
\hline \multicolumn{3}{|c|}{ Classe III - R \$ 144,00 } \\
\hline Alecrim & Canemuçu & Mamica-de-porca \\
\hline Angico-brano & Carne-de-vaca & Pessegueiro-brabo \\
\hline Cabreúva-falsa & Caxeta-amarela & Rabugio \\
\hline Camboatá & Farinha-seca & Vassourinha \\
\hline Canela do brejo & Fruta-macuco & Tarumão \\
\hline Canela-guaicá & Guabijú & Timbó \\
\hline Canela-pinho & Loro-branco & \\
\hline Canela-veado & Maria preta & \\
\hline \multicolumn{3}{|c|}{ Classe IV - R \$ 110,00 } \\
\hline Corticeira & Paineira & Tanheiro/canela-raposa \\
\hline Leiteiro & Pau-amargo & \\
\hline \multicolumn{3}{|c|}{ Exóticas - R\$ 119,00 } \\
\hline $\begin{array}{l}\text { Eucaliptos (Eucalyptus spp.) } \\
\text { Pinus (Pinus spp.) }\end{array}$ & \multicolumn{2}{|c|}{ Uva-japão (Hovenia dulcis Thumb.) } \\
\hline
\end{tabular}

\section{DISCUSSÃO}

As mudanças tecnológicas no setor madeireiro, que ocorreram a partir da década de 1960, ampliaram a maior devastação florestal na região do Alto-Uruguai-SC. Assim, em um curto período de tempo (1970-85), a pujante floresta reduziu-se a poucos fragmentos que totalizavam aproximadamente menos de 3\% da cobertura original (Fundação SOS Mata Atlântica, 1998). A Floresta Estacional Decidual passou então a se constituir na tipologia florestal mais ameaçada no Estado. Da mesma forma, nenhuma área da Floresta Estacional Decidual está sob proteção legal de domínio público, e, no geral, os remanescentes estão distribuídos em pequenos fragmentos, em áreas de relevo geralmente muito acidentadas.

Na região do Alto-Uruguai, no período inicial da colonização, a cobertura florestal foi de grande importância. A floresta era utilizada como propaganda pelas companhias colonizadoras para atrair novos migrantes e era vista como uma forma de gerar lucros para os proprietários das colonizadoras, para os madeireiros e os próprios colonos (Nodari, 1999). O comércio dos recursos madeiráveis era inicialmente restrito à troca das toras por madeira serrada para uso na propriedade. E, em áreas próximas ao rio Uruguai, ocorria a exportação de madeiras, por balsas, para a Argentina. Com o aumento da demanda e os avanços tecnológicos houve o fortalecimento do mercado madeireiro, o qual começou a pagar em moeda corrente pelo recurso florestal.

O conhecimento popular da diversidade de espécies florestais é dado em função do valor de uso e comercial destas. Da mesma maneira, deduz-se que o fato das espécies citadas como as mais freqüentes não 
implica dizer que estas representaram as de maior densidade. Isto justifica, em parte, a diferença observada entre as respostas obtidas pelas diferentes categorias de informantes. Além disso, atribui-se aos componentes do extrato florestal dominante a tendência de considerá-los superiores, uma vez que estes proporcionavam o maior volume madeirável por planta entre todas as espécies residentes nessa floresta. Esse fato levou os entrevistados as considerarem as mais abundantes. Da mesma forma, supõe-se que as espécies de maior valor comercial e de uso, tais como: cedro, louro, cabreúva e guatambu, sofreram maior pressão de exploração, com impactos negativos sobre a diversidade genética e a abundância dessas espécies nesse ecossistema florestal.

$\mathrm{O}$ uso tradicional num passado muito recente, período em que tal uso se limitava à qualidade da madeira, condicionava o comércio apenas das espécies de apreciável valor de uso. Ao contrário, atualmente, as espécies que apresentavam restrições de uso no passado substituíram, em parte, as espécies escassas. Esse fato é evidenciado no beneficiamento atual da madeira, na qual, muitas das espécies hoje mencionadas como madeireiras, até os anos de 1970 não eram exploradas comercialmente. A maioria destas espécies foi considerada de baixa densidade florestal, com exceção de alecrim, maria-preta, canela-pinha, rabugio, pessegueiro-brabo e vassourinha que foram mencionadas como as de maior densidade. Dessa forma, atualmente, não há restrições quanto à exploração e comércio da madeira de menor qualidade. Por outro lado, o atual padrão de beneficiamento das espécies de alto valor destina-se para usos mais requintados, a exemplo da indústria moveleira ou usos específicos nas construções residenciais.

Com base nas informações etnobotânicas obtidas, as espécies de maior valor apresentaram um maior número de usos e eram as de maior densidade na floresta. Outras espécies apresentaram um pequeno número de usos e foram relacionadas como de baixa frequência na região, revelando também um menor valor comercial. Ainda, estas foram de conhecimento restrito para a maioria dos entrevistados. Portanto, levantase a hipótese de que o menor valor madeirável destas não pode ser atribuído somente às qualidades da madeira, mas também à baixa densidade dessas espécies. Dessa maneira, observou-se que as espécies de maior freqüência foram basicamente as mesmas para as diferentes categorias dos entrevistados. Isso explica o porquê dessa maior diversidade nas respostas a respeito de espécies de baixa densidade. Ainda que muitas dessas espécies não foram reconhecidas pela maioria dos informantes, elas são atualmente exploradas sem grandes restrições, como por exemplo: carobão, quina, canela-raposa, canemuçu, tajaúva, guabiju, pessegueiro-brabo, caxeta, louro-branco, leiteiro e caxeta-amarela.

Algumas espécies apresentaram densidade intermediária. Contudo estas, em sua grande maioria, eram as mesmas consideradas como de maior densidade em nível regional, sendo apenas importante em determinados locais como, por exemplo, as espécies rabo-de-bugio, angico-vermelho, canafístula, guatambu, pessegueiro-brabo, vassourinha e cabreúva.

A condição tecnológica e a escassez do recurso florestal aumentaram o uso e o valor econômico de espécies anteriormente não-usadas. Esse é o caso do coqueiro (Syagrus romanzoffiana (Cham.) Glassm.) que era usado nas construções rurais. Já as espécies rabugio, caxeta, carobão e entre outras espécies consideradas de madeira mole/branca, encontraram colocação no mercado somente a partir de 1970. Nesse período, além do incremento dessas espécies no mercado madeireiro, ocorreu também um melhor aproveitamento do recurso florestal explorado, pelo uso das plantas com diâmetro menor que $40 \mathrm{~cm}$. Ainda, com a expansão do agro-indústria na região, observou-se um incremento no uso energético, fazendo com que partes das árvores, com diâmetros inferiores para uso madeireiro, passassem a ser comercializadas na forma de lenha.

Da mesma maneira, as espécies guatambu e açoita-cavalo exibiram um incremento no seu valor comercial, em razão da qualidade da madeira para uso nas indústrias moveleiras. Por outro lado, caxeta, que até a década de 1970, foi considerada uma espécie sem valor comercial, atualmente, por causa da qualidade da sua madeira branca e de baixa densidade, apresentou valorização ascendente, em decorrência de seu uso crescente na indústria moveleira. De outro lado, o coqueiro, processado com facilidade em função da aplicação de tecnologia simples (machado/cunheira), representou, no passado, a principal espécie como fonte de ripas para telhados. Atualmente, outras espécies a substituíram nessa função, em consequiência da sua inadequação ao beneficiamento tecnológico.

Ciência Florestal, v. 13, n. 1, 2003 
Dados obtidos para as espécies florestais maiores de $20 \mathrm{~cm}$ de diâmetro, para as tipologias florestais do Estado, revelaram densidades de 69 árvores e volume total de $75 \mathrm{~m}^{3}$ por hectare para Floresta Estacional Decidual (Pélico Neto e Brena 1997), valores esses superiores àqueles obtidos neste trabalho (média de 43 $\mathrm{m}^{3}$ ). Parte dessa diferença pode ser explicada pela seletividade das espécies e diâmetros das árvores exploradas naquela época.

A grande variância para o volume florestal referenciada entre as madeireiras, neste trabalho, talvez possa ser explicada pelas diferenças edáficas entre áreas florestais, pela intensidade da exploração por diâmetro e pela especificidade da espécie florestal.

A política ambiental foi componente importante que contribuiu para a valoração dos produtos florestais. Assim, as restrições legais para a exploração florestal, impostas pelo Decreto 750, de 10 de fevereiro de 1993 e complementadas pela Resolução n. 001, de 31 de Janeiro de 1994, causaram forte impacto na produtividade e comércio das madeireiras, fato esse que contribuiu para o enfraquecimento e viabilidade econômica destas. A legislação ambiental anterior, código Florestal de 15 de setembro de 1965, apesar de também ter sido rigorosa e restritiva à exploração florestal, não havia sido cumprida até então, o que pouco influenciou o desempenho dessas madeireiras.

Um segundo componente, que contribui para a valoração do recurso florestal, se encontra associado ao volume comerciável. Nesse sentido, as espécies guatambu, cedro, açoita-cavalo e louro apresentam valor comercial maior aos observados para a madeira proveniente do cento-oeste e norte do Brasil. Tal oferta é dada sobretudo pelas indústrias moveleiras. Como dificilmente as madeireiras dispõem de um volume razoável e de uma única espécie requerida, a oferta de madeira das outras regiões citadas é competitiva.

As empresas para se manterem em atividade, aproximadamente, dois terços tiveram que se reestruturar adotando maior flexibilidade, melhorias no aproveitamento do recurso florestal e agregação de valor pelo beneficiamento da madeira bruta.

\section{CONCLUSÕES}

O valor de um recurso florestal é limitado pela sua oferta. Atualmente, com a escassez dos produtos florestais de qualidade superior, as espécies anteriormente pouco empregadas e que são também de baixa dominância conquistaram espaço no mercado. Por outro lado, observou-se que, na região da Floresta Estacional Decidual, ocorrem várias espécies economicamente valiosas que anteriormente foram indiscriminadamente exploradas. As demais espécies com qualidades inferiores foram consideradas, ao longo deste processo, como sendo de menor valor comercial e de uso.

Os resultados do presente trabalho demonstram claramente que os recursos genéticos são valorizados diferentemente em diferentes épocas. Dentre os fatores, que mais afetaram a alteração no valor, destacam-se a oferta e a demanda, a qualidade da madeira e os avanços tecnológicos e as propriedades de uso do produto.

Uma recomendação que emerge deste trabalho está associada à necessidade de aprofundamento dos estudos sobre a auto-ecologia das espécies de valor comercial, associados a estudos de estrutura genética de populações dessas espécies. Assim, em decorrência desses estudos, podem ser estabelecidos critérios para fundamentar não só o desenvolvimento de tecnologias de manejo de rendimento sustentado, como também a definição de estratégias mais adequadas para a produção de sementes e conservação genéticas desses recursos. Assim, a exploração dos recursos florestais deveria ser feita compatibilizando-se o uso de um sistema de manejo que possibilite tanto o retorno econômico quanto à conservação desses recursos.

\section{AGRADECIMENTOS}

Os autores agradecem a CAPES pela bolsa concedida a Ademir Roberto Ruschel. Rubens Onofre Nodari e Miguel Pedtro Guerra são bolsistas do CNPq.

\section{REFÊRENCIAS BLIBLIOGRÁFICAS}

BRACK, P.; BUENO, R.M.; FALKENBEERG, D.B. et al. Levantamento floristico do Parque Estadual do Turvo, Tenente Portela, RS, Brasil. Roessleria, Porto Alegre, v. 7, n. 1, p. 69-94, 1985. 
BELLANI, E.M. Madeiras, balsas e balseiros no Rio Uruguai Chapecó: UNOESC, 1996. 222p.

CARVALHO, P. E. R. Espécies florestais brasileiras: Recomendações silviculturais, potencialidades e uso da madeira. Brasília: EMBRAPA, Centro Nacional de Pesquisa Florestal, 1994. 640p.

CHAZDON, R.L.; COE, F.G. Ethnobotany of woody species in second-growth, old-growth, and selectively logged forests of northeastern Costa Rica. Conservation Biology, Geneva, v. 13, n. 6, p. 1312-1322, 1999.

Di STASI, L.C. Plantas medicinais: arte e Ciência. Um guia de estudo interdisciplinar. São Paulo: UNESP, 1996. 230p.

DIAS, L.L.; VASCONDELLOS, J.M.O.; SILVA, C.P. et al. Levantamento florístico de uma área da Mata Subtropical no Parque Estadual de Turvo, Tenente Portela, RS. In: CONGRESSO NACIONAL SOBRE ESSÊNCIAS NATIVAS, 2., 1992, São Paulo. Anais.... São Paulo: Instituto Florestal, 1992. v. 4, p. 339-347.

FUNDAÇÃO SOS MATA ATLÂNTICA. Atlas da evolução dos remanescentes florestais e ecossistemas associados no domínio da Mata Atlântica no período de 1990- 1995. São Paulo, 1998. 55p.

IBDF - Instituto Brasileiro de Desenvolvimento Florestal. Inventário Florestal Nacional: florestas nativas, Paraná, Santa Catarina. Brasília: IBDF, 1984. 309p.

IBGE - Instituto Brasileiro de Geografia E Estatística. Geografia do Brasil. Região Sul. Rio de Janeiro: IBGE, 1990. v. 2. 419p.

INSTITUTO DE GEOGRAFIA E ESTATÍSTICA. Informações estatísticas do Município de Chapecó - relativas ao ano de 1940. Cruzeiro: Empresa Gráfica Cruzeiro, 1942. (Informação n. 30 - $4^{\stackrel{a}{ }}$ Divisão Técnica).

INSTITUTO CEPA - INSTITUTO DE PLANEJAMENTO E ECONOMIA AGRÍCOLA DO ESTADO DE SANTA CATARINA. Informe Conjuntural, Florianópolis, v. 17, n. 728, 1999. 10p.

KLEIN, R.M. Árvores Nativas da Floresta Subtropical do Alto Uruguai. Sellowia, Itajaí, v. 24, p. 9-62, 1972.

LINDMAN, C. A. M. A Vegetação no Rio Grande do Sul. 2. ed. São Paulo: Itatiaia, 1974. 377p.

LORENZI, H. Árvores brasileiras: manual de cultivo de plantas arbóreas nativas do Brasil. 2. ed. Nova Odessa: Editora Plantarum, 1998. v. 1-2.

NODARI, E.S. A renegociação da etnicidade no Oeste de Santa Catarina (1917-1954) 1999. 322p. Tese (Doutorado) Programa de Pós-graduação em História, Pontifícia Universidade Católica do Rio Grande do Sul, Porto Alegre, 1999.

PÉLLICO NETO, S.; BRENA, D.A. Inventário Florestal. Curitiba: Edição dos autores, 1997. 316p.

RAMBO, B. Der Regenwald am oberen Uruguay. Sellowia, Itajaí, v. 7, p. 183- 223, 1956.

REITZ, P. R.; KLEIN, R.M. Os nomes populares das plantas de Santa Catarina.Sellowia, Itajaí, v. 16, p. 9-118, 1964.

REITZ, R.; KLEIN, R.M.; REIS, A. Projeto madeira de Santa Catarina.Sellowia, Itajaí, v. 28, p. 1-320, 1978.

SIQUEIRA, J.D.P. Expressão econômica e social das essências nativas. In: CONGRESSO NACIONAL SOBRE ESSÊNCIAS NATIVAS, 1., 1982, Campos do Jordão, SP. Anais..., Campos do Jordão-SP: Instituto Florestal, 1982. $1444 \mathrm{p}$.

THOMÉ, N. 1949-Ciclo da madeira: história da devastação da floresta da araucária e do desenvolvimento da indústria da madeira em Caçador e na região do Contestado no século XX. Caçador: Universal, 1995. 212p.

Ciência Florestal, v. 13, n. 1, 2003 